\title{
EAl Endorsed Transactions

\section{The use of digital educational resources in the support to learning in higher education}

\author{
Carlos Morais ${ }^{1,2}$, Luísa Miranda ${ }^{1,2}$ and Paulo Alves ${ }^{2}$ \\ ${ }^{1}$ Centro de Investigação em Estudos da Criança (CIEC), Universidade do Minho, Portugal \\ ${ }^{2}$ Instituto Politécnico de Bragança, Bragança, Portugal
}

\section{Abstract}

This paper aimed to assess the importance given to the use of digital educational resources, their use frequency, and their classification considering them as a support to course units. The data was obtained through questionnaire and provided by a sample of undergraduates. We reflected on the concept of digital educational resource and presented the results of a study assessing the importance given by undergraduates to digital educational resources as well as their classification as a support to learning concerning aspects associated with learning strategies, motivation and learning tasks. We used research methodologies associated with both the quantitative and the qualitative paradigms. The results showed the existence of significant differences, between the 1 st and the 2 nd year students regarding the item study alone. The characterization of digital educational resources was made based on the answers given to open-ended questions and their further classification.

Keywords: digital resources, digital educational resources, importance of digital educational resources, classification of digital educational resources.

Received on 15 October 2014, accepted on 11 January 2015 , published on 17 March 2015

Copyright (C) 2015 C. Morais et al., licensed to ICST. This is an open access article distributed under the terms of the Creative

Commons Attribution licence (http://creativecommons.org/licenses/by/3.0/), which permits unlimited use, distribution and reproduction in any medium so long as the original work is properly cited.

doi: $10.4108 / \mathrm{el} \cdot 2.5 . \mathrm{e} 5$

\section{Introduction}

More than ever before, technology is influencing both directly and indirectly the various contexts in which people happen to find themselves, particularly the higher education teaching and learning context. Among the several aspects deserving and justifying scientific research within this particular context, we highlight the use and assessment of resources supporting the teaching and learning process. The search for good practices challenges teachers and researchers to look for teaching and learning strategies which can make the process more appealing and the learning more effective. In general, many of the strategies are supported by educational resources associated with information and communication technologies (ICT).

The implementation of teaching and learning strategies with innovative resources must take place with the involvement of its main parties, teachers and students. This paper gives special focus to the use of digital educational resources by undergraduates assessed based on quantitative and qualitative data provided by a sample of 315 students from a Portuguese state higher education institution.
Bearing in mind that all the students are from the same institution, there is no intention to generalize the results within the scope of higher education. However, they can represent secure indicators in the identification and understanding of the importance and use frequency of digital educational resources by undergraduates. Therefore, the main aims of this study are:

- Assess the importance given by undergraduates to digital educational resources in the support to learning;

- Verify the existence of significant differences in the importance given to the resources between curricular years;

- Assess the use frequency of digital educational resources by undergraduates;

- Verify the existence of significant differences in the use frequency between curricular years;

- Classify the digital educational resources as well as their use in the support to course units.

The data that enables the achievement of these aims was obtained from the students' answers to a questionnaire built and validated for this purpose and administered in the 2013/2014 academic year. In 
this paper we present the theoretical framework behind digital educational resources, the study methodology, the results, the conclusions and finally, the references.

\section{Digital educational resources}

Achieving the highest level of learning in the shortest time possible and with the lowest effort is a challenge that education and training institutions are trying to overcome. As Davidson and Goldberg [1] point out, an important share of the future of learning lies in the development of methods that distinguish the good sources of knowledge from the questionable ones. More and more, learning is about how to make the wise choices, epistemologically, methodologically and regarding cooperation partnerships in order to approach complex challenges and problems.

Within the information society, it is important that people can use ICT and digital resources in their professional life as well as in their various roles as citizens. According to Ramos, Teodoro, Fernandes, Ferreira, and Chagas [2], educational resources follow the evolution of society, having evolved in almost all education levels in a similar way to the evolution of society: the printed material models gave place to digital models, thus following the change of technologies and their role in society. Also, in the information society, we are awash with information, tools, knowledge and resources coming from all the regions in the world and from the most diverse communities and cultures.

In the same sense, Littlejohn, Falconer and Mcgill [3] highlight that over the last decades, we have witnessed huge changes in teaching methods and new types of resources available, all based on digital technologies.

The existence of a big quantity and diversity of resources and information flows coming from various sources and in various formats poses new challenges to educational institutions as far as the new directions of teaching and learning are concerned. Institutions are no longer capable of providing all the resources which their inner communities need, which implies a special concern with processes which may lead to a search for the best possibilities to benefit from what exists within a context increasingly more global and with more potentialities. Cesteros, Romero and Ranero [4] point out that among the issues worrying teachers and educational institutions is the need to have good didactic materials in digital format so that they can be used in the teaching and learning virtual environments, as one of the quality criteria of an educational institution's e-learning modalities is related to the provision of good quality digital didactic resources.

The selection of good resources is not made without the involvement and effort of the main stakeholders. Dahlstrom, Walker, and Dziuban [5] state that in order to find the way to best integrate technology in academic environments, partnerships must be held between students, teachers and the institution they are part of. Similarly, Ramos, Teodoro, and Ferreira [6] suggest that a considerable part of the impact, either positive or negative, of the use of technology on the student's learning depends on the context and the actors involved, namely the teachers and the learning situations and experiences that they can create from using technologies.

As suggested by Connaway, Lanclos, and Hood [7], people are less and less dependent on the resources and technologies provided by their institutions because they have easier access to internet connection and devices which allow access to the open web and to its countless free sources, and subsequently to a much wider level of information. The importance of accessing the web and its resources is shown by Wetzler, Bethard, and Leary [8] when they refer that Americans spend 138 million hours a year doing research on the web to select resources.

The resources deserving great attention from institutions, researchers, teachers and students nowadays are digital educational resources. However, the question which must be answered in the first place by any individual or institution is: What are digital educational resources? Considering the complexity of the concept and the dimensions that it involves, it is not easy to obtain one single and consensual definition. Nevertheless, it is important that concepts are defined so that their meaning can be shared by wide communities of users.

In order to contribute for a definition of digital educational resources, Ramos, Teodoro, and Ferreira [6] present some characterizations which may be admitted as definitions in certain contexts. Thus, they consider digital educational resources as digital entities produced specifically for purposes of support to teaching and learning. These authors claim that within a broader perspective, they may include all types of digital resources possessing an intrinsic educational intention, thus increasing the quantity of resources available to the community, namely teachers, students and families.

Tackling the concept of digital educational resource more specifically, Ramos, Teodoro, 
Fernandes, Ferreira, and Chagas [2] present it as: an artefact stored and accessible in a computer, conceived for educational goals and possessing not only identity and autonomy from other objects but also appropriate quality patterns. Examples of such a definition are: programs and applications designed specifically for educational purposes and collections of digital resources which can be used to enhance learning. Yang [9] refers that digital resources include digital video, digital audio, multimedia software, sites, learning management systems, simulation programs, online discussions and databases.

Carneiro, Rodrigues, Matos, Almeida, and Melo [10] define digital educational resources according to the nature of their coding, their relevance and their use as a driving force of ICT for renewing and improving learning contexts. They consider them as products in digital format meant for learning contexts as well as support services to their use.

Similarly, Cesteros, Romero, and Ranero [4] present the concept of digital didactic material, which they define as a resource in digital format used in the teaching and learning process. This may be any digital material that the teacher or the student uses within a curricular unit, namely a program, calendar, lesson plan, notes, activities or tutorials. Fernández-Pampillón [11] highlights the Spanish norm UNE 71361:2010, which defines digital educational resource as any entity which can be used for learning, education and training.

Hylén [12] presents the following advantages of using digital educational resources to support learning over traditional materials:

- They offer the possibility of a greater individualization of learning;

- Their production is cheaper and they can easily be updated;

- The use of multimedia characteristics can offer different types of learning stimuli to different students;

- They enable a higher individualized interaction and discussion;

- The combination of multimedia characteristics increases the chances of showing experiments which would be difficult to carry out without using simulations, videos, animations, among others.

According to Pinto [13], digital educational resources can be classified within the following categories: educational software, educational platforms, portals of contents, learning tutorials, electronic files and thematic resources directories.
Digital educational resources also appear associated with learning objects and educational objects. According to Wiley [14], a learning object is any digital resource that can be used to support teaching.

Digital educational resources are defined by Tarouco [15] as any supplementary resource to the learning process which can be reused to support learning.

Learning objects and educational objects have several similarities to digital educational resources, namely their goals of learning a content, topic or concept, and also in terms of their use, as they can also be used in websites or in learning management environments. The main difference may lie in the way they are structured and can be reused, as learning objects have this concern in their genesis whereas digital educational resources do not.

One of the most relevant aspects in the selection, acquisition, use or sharing of a digital educational resource has to do with its quality. The concept of quality involves multiple variables and often depends on the aims to be achieved with the resource, the context in which it is used and the way it may be obtained. Wetzler, Bethard, and Leary [8] refer that in order to determine which quality aspects are the most important to users within a particular domain, it is necessary to admit that the quality of a web resource includes many factors which all together create a better whole. The authors point out that quality is a multifaceted concept and that different aspects of quality may be relevant to different users, in different moments. Among the results presented by the authors, we highlight several criteria to measure the quality of a digital educational resource such as: user-friendliness, trustfulness, credibility, exactness, reliability, erudition, scientific rigor, text quantity, text positioning, and charts quantity and quality.

Regarding the quality of digital educational resources, Fernández-Pampillón [11] points out that it has to do with educational and technological efficiency features. The author associates educational efficiency with the capacity of the resource to enhance the teaching and learning process and consequently improve academic performance, whereas technological efficiency is related to the possibility or not of being a good ICT product: reliable, portable and scalable.

It is crucial to promote the use of digital educational resources within educational communities, especially among students, as according to Dahlstrom, Walker, and Dziuban [5], the relation between students and technology is 
complex, as they recognize its value but they still need support when it comes to using it better for academic purposes. However, they value the ways in which technology helps them achieve their academic goals and prepares them for their academic and professional future.

We believe that the introduction of qualitative aspects in research works can enrich them and provide data that the quantitative methodology cannot provide. Therefore, even agreeing that it is necessary to admit some subjectivity in the treatment of qualitative data, we chose to approach qualitative aspects in this paper.

When we have a set of qualitative data, it is important to give it a practical and useful sense, organizing it by identifying each of its parts and grouping it so as to be able to distinguish between the most representative information and the least representative of each topic under study. Thus, considering the information under analysis, which may be a text, a book, a set of answers to a question or a set of answers to a questionnaire, among others, the following question arises: how can we measure this magnitude (set of information)? Usually, in order to measure a magnitude, we select a unit and then verify how many times the chosen unit "fits" in the magnitude being measured, considering that number of times the measure of the magnitude.

Moraes [16] refers the following stages within the content analysis process: preparation of the information, transformation of the content into units, categorization, description and interpretation.

Within the context of content analysis, and considering a set of information for analysis, we designated as analysis unit the minimal unit which allows us to break down the whole information into several units. We identified each unit from the minimal unit and called them record units. After organizing the record units into classes according to clearly defined criteria, we obtain categories. Thus, each category is a class composed of a set of record units which have a similar sense or meet the same association criteria.

According to Bardin [17], the analysis unit is the significance unit to be codified and corresponds to the segment of content to be considered as the base unit, intending the categorization, the counting and the frequency. In other words, we can consider as analysis unit the minimal unit of information which enables to codify the information under analysis within a set of other units, each of which will be called record unit. The same author adds that the categorization is an operation of classification of elements included in a set through differentiation and through regrouping according to previously defined criteria. The categories are classes which integrate the record units. These elements are grouped due to the fact that they share certain characteristics in an attempt to present the meaning of the raw data in a condensed and simplified way.

Moraes [16] considers categorization as a procedure to group data considering what there is in common between its parts. Classification takes place by similarity or analogy, according to criteria established or defined previously in the process.

After organizing a set of information within a set of categories, the latter must verify at least two essential characteristics: exclusivity and completeness. Exclusivity ensures that there is no record unit belonging to more than one category; completeness ensures that each record unit identified within the set of information was integrated in some category.

Content analysis is essential when researchers follow the qualitative research paradigm. Qualitative research is quite complex at times due to the various dimensions it involves as well as the difficulty in defining the analysis unit and in codifying the record units in coherence with the analysis unit.

Therefore, we included a qualitative component in this paper in order to provide a better understanding of the importance given by students to digital educational resources.

\section{Methodology used}

The study assumes both a quantitative and a qualitative approach. Quantitative research is an approach which enables to test the relation between variables. These variables may be measured by tools which provide numerical data which can be analyzed by statistical procedures [18]. According to Kumar [19], a study can be considered quantitative when it intends to quantify the variation of a phenomenon, situation, problem or question, when the information is obtained from variables predominantly quantitative, and the data analysis is oriented towards the assessment of its variation magnitude.

The qualitative approach implies essentially the definition of analysis units, record units and categories and the integration of the record units into the respective categories.

The data was obtained through a questionnaire built by the authors of the study and subsequently validated, composed of closed-ended questions, thus making the variables involved in the research assume whole numerical figures. The questionnaires were administered within the classroom context and 
entire classes were questioned. The questionnaires were filled in at the beginning of one of the lessons of each class involved with the previous authorization of the teachers as well as the presence of at least one of the researchers. The sample was non-probabilistic as the selection was not random. However, an effort was made so that it would be representative of the whole of undergraduates enrolled in the two schools where the data was obtained, namely the school of Education and the school of Technology and Management. In the school of Education, there were 1617 students enrolled in the 2013/2014 academic year and 210 students answered the questionnaire. In the school of Technology and Management, there were 2285 students enrolled in that same year and 105 answered the questionnaire.

Thus, among a population of 3902 a sample of 315 subjects was extracted which corresponds to approximately $8 \%$ of the population.

Among the characteristics of the sample we highlight: 93 (29.5\%) are male and $222(70.5 \%)$ are female. The mean age is 20.8 years old, the mode and the median are 20 years old and the standard deviation is 2.7 .

Among the sample subjects, 161 (51.1\%) were enrolled in the 1st year, 70 (22.2\%) in the 2 nd year and $84(26.7 \%)$ in the 3rd year.

Another feature considered in the sample characterization regards their IT knowledge. The data was obtained from the answers to the question: Classify your general IT knowledge (mark only one option): a) Basic; b) Intermediate; c) Advanced.

The results obtained from the answers to this question are presented in Table 1.

Table 1. Classification of the sample subjects' IT knowledge

\begin{tabular}{lll}
\hline IT knowledge & $\mathbf{n}$ & $\mathbf{\%}$ \\
\hline Basic & 90 & 28.6 \\
Intermediate & 199 & 63.2 \\
Advanced & 24 & 7.6 \\
Doesn't answer & 2 & 0.6 \\
\hline
\end{tabular}

Considering the data presented in Table 1, we see that the majority of subjects classified their IT knowledge as intermediate (63.2\%). The others consider to have basic IT knowledge (28.6\%) and advanced knowledge (7.6\%).

\section{Results of the assessment of the importance and use of digital educational resources by undergraduates}

The results were treated according to the aims defined for the research. Therefore, we present the data and the respective interpretation regarding: the importance that students give to digital educational resources in the support to learning, and the use frequency of digital educational resources.

Throughout the treatment of data, not only will we highlight the results related to the whole sample but we will also give particular attention to the students' evolution regarding their relationship with digital educational resources by analyzing the results according to the curricular year in which the sample subjects are enrolled.

\subsection{The importance of digital educational resources in the support to learning}

The importance of digital educational resources in the support to learning was assessed from the answers given to the following question: Mark with a cross (X) the option which best translates the importance that you give to digital educational resources in the support to learning for the items presented in Table 2 .

Table 2. Digital educational resources in learning $(n=315)$

\begin{tabular}{|c|c|c|c|c|c|c|}
\hline $\begin{array}{l}\text { Digital educational } \\
\text { resources are } \\
\text { important to: }\end{array}$ & $\begin{array}{l}\text { DA } \\
(\%)\end{array}$ & $\begin{array}{l}\mathrm{NI} \\
(\%)\end{array}$ & $\begin{array}{l}\mathrm{LI} \\
(\%)\end{array}$ & $\begin{array}{l}\mathrm{IM} \\
(\%)\end{array}$ & $\begin{array}{l}\text { VI } \\
(\%)\end{array}$ & $\begin{array}{c}\text { EI } \\
(\%)\end{array}$ \\
\hline Study alone & 0 & 0.6 & 3.2 & 30.5 & 40.3 & 25.4 \\
\hline Work in group & 0 & 0.3 & 2.2 & 23.5 & 52.1 & 21.9 \\
\hline Do classroom activities & 1.9 & 0 & 2.2 & 23.2 & 50.2 & 22.5 \\
\hline $\begin{array}{l}\text { ties outside the } \\
\mathrm{m}\end{array}$ & 1.0 & 0 & 3.5 & 26.7 & 44.8 & 24 \\
\hline & 0 & 0.6 & 1.3 & 21.0 & 43.2 & 34.0 \\
\hline $\begin{array}{l}\text { Improve the taste for } \\
\text { research }\end{array}$ & 0.6 & 0.6 & 1.6 & 21.6 & 45.7 & 29.8 \\
\hline Increase knowledge & 0.3 & 0 & 0.3 & 11.4 & 42.2 & 45.7 \\
\hline Clarify & 1.0 & 0 & 0.6 & 14.0 & 39.0 & 45.4 \\
\hline $\begin{array}{l}\text { Improve written } \\
\text { communication }\end{array}$ & 0.6 & 1.3 & 4. & 24.4 & 43 & 25.7 \\
\hline & 0.6 & 1.6 & 7.9 & 24.8 & 5 & 28.6 \\
\hline Interpret texts & 1.0 & 0.3 & 4.8 & 27.0 & 39.0 & 27.9 \\
\hline
\end{tabular}

Caption: DA - Doesn't Answer, NI - Not Important, LI - of Little Importance, IM - Important, VI - Very Important, EI - Extremely Important. 
The options considered were: not important, of little importance, important, very important and extremely important. The assessment of the importance regarding the support to learning was analyzed widely and involved several aspects such as learning strategies, motivation and learning tasks.

In order to better interpret the sample subjects' answers, we decided to give a number to each option of answer. The options were numbered as follows: 0 - doesn't answer; 1 - not important; 2 - of little importance; 3 - important; 4 - very important; 5 extremely important. According to this convention, we present in Table 2 the percentages regarding the distribution of answer scores for the several items under analysis.

Considering the data presented in Table 2, the recognition of the importance of digital educational resources was widely accepted, as in all the aspects under analysis, over $65 \%$ of the answers fell on the options very important and extremely important.

By adding up the percentages obtained in the options very important and extremely important, we conclude that the importance of resources according to the support they can provide to learning ranging from the most important to the least important is as follows: increase knowledge; clarify doubts; improve learning willingness; improve the taste for research; work in group; do classroom activities; improve written communication; do activities outside the classroom; interpret texts; study alone; improve oral communication.

Bearing in mind that the study involved subjects enrolled in the 1st, 2nd and 3rd curricular years, we analyzed the way the year in which each subject was enrolled influenced the importance given to resources in the support to learning. Thus, and considering the convention of the numerical value given to each option of answer, which makes the answer of each subject to each item assume a value ranging from zero to five, we were able to find the mean of the score given by the sample subjects from each curricular year to each one of the items under analysis. The distribution of means by curricular year is presented in Table 3 .

Considering the data in Table 3, it is clear that the students in the 2nd year are those who most value digital educational resources to: interpret texts, clarify doubts, increase knowledge, do activities outside the classroom, work in group and study alone. On the other hand, the students in the 1st year appear to value more digital educational resources to improve oral communication and do classroom tasks. The students in the 3rd year do not seem to stand out in any of the items, but give most importance, with the same score as 2nd year students, to the items: improve the taste for research and improve learning willingness.

Table 3. Score means regarding the importance given to digital educational resources in the support to learning

\begin{tabular}{lccc}
\hline $\begin{array}{l}\text { Digital educational resources } \\
\text { are important to: }\end{array}$ & 1st Year & $\begin{array}{c}\text { 2nd } \\
\text { Year }\end{array}$ & 3rd Year \\
\hline Study alone & 3.77 & 4.11 & 3.85 \\
Work in group & 3.88 & 4.07 & 3.92 \\
Do classroom activities & 3.91 & 3.84 & 3.83 \\
Do activities outside the classroom & 3.78 & 4.01 & 3.92 \\
Improve learning willingness & 4.00 & 4.17 & 4.18 \\
Improve the taste for research & 3.96 & 4.06 & 4.06 \\
Increase knowledge & 4.29 & 4.40 & 4.32 \\
Clarify doubts & 4.27 & 4.33 & 4.20 \\
Improve written communication & 3.93 & 3.90 & 3.71 \\
Improve oral communication & 3.89 & 3.76 & 3.68 \\
Interpret texts & 3.84 & 3.96 & 3.83 \\
\hline
\end{tabular}

In order to assess whether there were any significant differences in the importance given to digital educational resources depending on the curricular year that students are enrolled in, we used the Levene test to analyze the variances in the distribution of data regarding each curricular year, and we used Student's $t$ test to assess the existence of significant differences between the means of each pair of groups. Thus, we compared the data regarding each item between 1 st year and 2 nd year students, between 1 st and 3rd year students and finally, between 2 nd and 3 rd year students.

In all the comparisons made, significant differences were found only between the groups of 1 st and 2nd year students regarding the item study alone, to which 2nd year students appear to give more importance.

After analyzing the importance given to digital educational resources in the support to learning, we analyzed the use frequency of such resources by the same sample subjects.

\subsection{Use frequency of digital educational resources by undergraduates}

The use frequency of digital educational resources was measured from the answers given to the question: Mark with a cross (X) the option which best translates the use that you make of the items: video websites, online encyclopedias, blogs, wikis, 
scientific repositories, social networks, e-learning platforms, discussion forums, and searching engines.

The options of answer associated with each resource were: never, few times, sometimes, many times, and always. Reading and interpreting data which involves simultaneously several variables and options of answer for each variable is not straightforward. Therefore, we chose to give each option a number, thus giving sense to the use frequency of each resource with one single score. The numbers given to each option of answer were as follows: 0 - doesn't answer; 1 - never; 2 - few times; 3 - sometimes; 4 - many times; 5 - always. This way, the assessment of the use frequency of each resource was made by analyzing the means resulting from the defined scoring. The distribution of data regarding the whole of the answers is presented in Table 4.

Table 4. Use frequency of the resources in the support to learning $(n=315)$

\begin{tabular}{|c|c|c|c|c|c|c|}
\hline Resources & $\begin{array}{l}\mathrm{DA} \\
(\%)\end{array}$ & $\begin{array}{l}\mathrm{NE} \\
(\%)\end{array}$ & $\begin{array}{l}\text { FT } \\
(\%)\end{array}$ & $\begin{array}{l}\text { ST } \\
(\%)\end{array}$ & $\begin{array}{l}\text { MT } \\
(\%) \\
\end{array}$ & $\begin{array}{l}\mathrm{AL} \\
(\%) \\
\end{array}$ \\
\hline Video websites & 1.0 & 1.0 & 14.0 & 30.5 & 43.8 & 9.8 \\
\hline $\begin{array}{l}\text { Online } \\
\text { encyclopedias }\end{array}$ & 1.0 & 4.8 & 26.3 & 39.7 & 23.5 & 4.8 \\
\hline Blogs & 0 & 9.5 & 32.1 & 38.7 & 16.8 & 2.9 \\
\hline Wikis & 1.3 & 11.7 & 18.7 & 40.0 & 21.9 & 6.3 \\
\hline $\begin{array}{l}\text { Scientific } \\
\text { repositories }\end{array}$ & 2.5 & 12.4 & 26.3 & 31.7 & 21.3 & 5.7 \\
\hline Social networks & 1.9 & 6.3 & 14.0 & 14.9 & 29.5 & 33.3 \\
\hline $\begin{array}{l}\text { E-lea } \\
\text { platfo }\end{array}$ & 2.2 & 9.2 & 21.9 & 35.9 & 22.2 & 8.6 \\
\hline $\begin{array}{l}\text { Discussion } \\
\text { Forums }\end{array}$ & 1.3 & 20.6 & 39.0 & 24.4 & 11.1 & 3.5 \\
\hline $\begin{array}{l}\text { Searching } \\
\text { engines }\end{array}$ & 1.3 & 1.9 & 1.6 & 9.8 & 39.0 & 46.3 \\
\hline
\end{tabular}

Caption: DA - Doesn't Answer; NE - Never, FT - Few Times, ST - Sometimes, MT - Many Times, AL - Always

After analyzing the data in Table 4, we concluded that all the resources under assessment were used by at least some of the students. The information that stands out is that searching engines were used many times or always by over $85 \%$ of the sample subjects and that video websites and social networks were used many times or always by more than $50 \%$ of the sample subjects, whereas discussion forums were used many times or always by only $14.6 \%$ of the sample subjects.

Connaway, Lanclos and Hood [7] point out that according to the opinion of students themselves, they look for information by using internet resources such as searching engines and social networks more often than in physical spaces. They add that the dependence on digital spaces coexists with the constant need students have to be in touch with other people, whereas it is online or in person. Personal networks and the relationships which compose them are important factors regarding the strategies for searching information.

After a global analysis of the frequency use of digital educational resources by the sample subjects, we went on to assess whether or not that frequency was influenced by the curricular year in which students were enrolled. Considering the scoring means of the use of each resource from the zero to five scale which was established, we assessed the existence of significant differences between the referred means according to the respective curricular years. In Table 5, we present the data regarding each group of sample subjects, namely the 1st, 2 nd and 3rd year students.

Table 5. Means of use frequency of the resources in the support to learning (range 0 to 5 points)

\begin{tabular}{lccc}
\hline Resources & 1st Year & 2nd Year & 3rd Year \\
\hline Video websites & 3.48 & 3.54 & 3.3 \\
Online encyclopedias & 2.78 & 3.16 & 3.07 \\
Blogs & 2.6 & 2.96 & 2.74 \\
Wikis & 2.94 & 2.81 & 2.85 \\
Scientific repositories & 2.52 & 3.01 & 2.93 \\
Social networks & 3.66 & 3.87 & 3.4 \\
E-learning platforms & 2.72 & 3.2 & 3.08 \\
Discussion Forums & 2.22 & 2.33 & 2.57 \\
Searching engines & 4.2 & 4.23 & 4.27 \\
\hline
\end{tabular}

By observing Table 5, we can see that the 3rd year students are the ones who presented the highest use frequency of searching engines and discussion forums; 2nd year students presented the highest frequency use of e-learning platforms, social networks, scientific repositories, blogs, online encyclopedias and video websites; 1st year students presented the highest frequency use only regarding wikis. This result concerning 1 st year students deserves some reflection, especially on the type of wikis that students use the most before entering higher education and what are the reasons which influence the decrease of interest in wikis throughout higher education.

In order to analyze whether or not the difference between the means was significant, we used the 
Levene statistical test to assess the equality of variances and Student's t test to assess the equality between the means.

When comparing the scoring means of 1 st and 2nd year students, we assumed the equality of variances by applying Levene's test, thus it was not possible to reject the null hypothesis with a significance lower than 5\%, in all variables except the variable social networks. By applying the $t$ test to the variables in which we assumed the equality of variances between the distribution of data, we concluded that there were significant differences between the two groups of students in the variables online encyclopedias (Sig. 0.009), blogs (Sig. 0.006), scientific repositories (Sig. 0.003), and elearning platforms (Sig. 0.003). In all the situations mentioned, the group which presented the highest use frequency was the 2 nd year subjects group.

When comparing the 1st and 3rd year subjects, and combining the Levene test of the equality of variances with the application of the $t$ test for the equality between means, we concluded that there were significant differences between the two groups in the variables online encyclopedias (Sig. 0.025), scientific repositories (Sig. 0.008) and e-learning platforms (Sig. 0.020). In all the situations mentioned, the group with the highest use frequency was the 3 rd year subjects group.

By following the same procedures to compare the groups of 2 nd and 3rd year subjects, we concluded that there were significant differences between the groups only in the variable social networks (Sig. $0.023)$. In this case, 2nd year subjects presented a higher use frequency than the 3 rd year ones.

To sum up, with the exception of social networks, in all the cases in which significant differences were found, the higher is the curricular year in which the subjects are enrolled, the higher the use frequency of resources supporting learning is.

\subsection{Classification of digital educational resources and of their use in the support to course units by undergraduates}

The presentation of results concerning the classification of digital educational resources and of their use to support course units follows a qualitative approach. Therefore, we defined an analysis unit, identified record units, defined categories and integrated the record units into the respective categories.

The results regarding the classification of digital educational resources and of their use in the support to course units were obtained from the answers given by the sample students to the question: Highlight two adjectives which classify: a) The use of educational resources in the support to course units; b) Digital educational resources.

After reading all the answers and after assessing which analysis unit best translated the subjects' answers so as to enable their categorization, we defined as analysis unit: "each adjective identified in the answers given by the subjects who participated in the study". This analysis unit enabled us to identify all the adjectives in the answers, each of which was identified as a record unit.

Not all the sample students answered the given question. Among the 315 sample students, 155 sample subjects $(49.2 \%)$ answered point a), whereas 135 sample subjects (42.9\%) answered point b). In the answers given to point a), we identified 266 record units, whereas in the answers given to point b), 223 record units were identified.

Bearing in mind that the main aim of asking the question presented was to obtain from students the classification of digital educational resources and of their use in the support to course units, on the whole of all the record units, we defined for each point a) and b) the following categories: support to learning; resources specificities; resources potentialities; and others.

Considering the fact that the adjectives used by students to characterize digital educational resources and their use in the support to course units were the same ones, we defined the same categories for the answers to both points a) and b).

We hereafter present the definition of each one of the categories mentioned as well as examples of the adjectives which compose them:

- Support to Learning: it includes all the adjectives which translate aspects regarding the global characteristics of the resource or of its use. Examples: support, help, essential, important, useful, crucial;

- Resources Specificities: it includes all the adjectives which translate specific aspects or characteristics of the resources or of their use. Examples: appealing, flexible, enthralling, practical, quick, and simple;

- Resources potentialities: it includes all the adjectives which translate potentialities associated with the resources or their use. Examples: research, cooperation, exploration, communication and interaction; 
- Others: it includes all the adjectives which were not included in the previous categories. Examples: fair, free.

In Table 6, we present the distribution of the record units identified in students' answers among the respective categories.

Table 6. Classification of the use of digital educational resources in the support to course units $(n=266)$

\begin{tabular}{lll}
\hline Categories & \multicolumn{2}{l}{ Record Units } \\
\cline { 2 - 3 } & N. of units & $\%$ \\
\hline Support to learning & 144 & 54.1 \\
Resources specifities & 98 & 36.8 \\
Resources & 22 & 8.3 \\
potentialities & 2 & 0.8 \\
\hline
\end{tabular}

In the light of the data presented in Table 6, we can conclude that the majority of students associate the use of digital educational resources with the support to learning, with a significant representativeness of the percentage of adjectives associated with the specific characteristics of each digital educational resource.

In Table 7, we present the distribution of the record units identified in the answers among the respective categories.

Table 7. Classification of digital educational resources $(n=223)$

\begin{tabular}{lll}
\hline Categories & \multicolumn{2}{l}{ Record Units } \\
\cline { 2 - 3 } & N. of units & $\%$ \\
\hline Support to learning & 89 & 39.9 \\
Resources specifities & 112 & 50.2 \\
$\begin{array}{l}\text { Resources } \\
\text { potentialities }\end{array}$ & 19 & 8.5 \\
Others & 3 & 1.3 \\
\hline
\end{tabular}

Considering the data presented in Table 7 , we conclude that given the number of record units included in each category, the most representative categories are Resources specificities and Support to learning, thus showing that students value the specific characteristics of each resource and the support to learning that each resource may provide within the course units.
To sum up, the adjectives associated with digital resources and with their use in the support to the teaching and learning process within the scope of course units can be integrated in the following categories: support to learning, specificities of digital educational resources, and potentialities of digital educational resources. According to the answers given by undergraduates, the most representative categories are the two first ones.

\section{Conclusions}

This paper presents results obtained from a study carried out in the 2013/2014 academic year, among a sample of 315 undergraduates from a Portuguese higher education institution. The data was obtained through a questionnaire containing both closedended and open-ended questions. The main aims of the study were: to assess the importance given by undergraduates to digital educational resources in the support to learning; identify the use frequency of digital educational resources in the support to learning; and classify digital educational resources according to the students' opinions translated into adjectives associated with digital educational resources and with their use. Among the results obtained from this study we highlight:

- Most subjects who participated in the study give great importance to digital educational resources to: increase knowledge, clarify doubts, improve learning willingness, improve the taste for research, work in group, do classroom activities, improve written communication, do activities outside the classroom, interpret texts, study alone, and improve oral communication. By comparing the referred aspects between the groups of students enrolled in the 1st, 2nd and $3^{\text {rd }}$ curricular years, we concluded that there are significant differences between the 1st and the 2nd year groups regarding the item study alone, to which the group of students in the 2 nd year gave more importance.

- The digital educational resources which are most used many times or always by over $50 \%$ of the sample subjects are: searching engines, social networks and video websites. By comparing the use frequency between the 1st and 2nd year groups, we found significant differences, with a level of significance lower than $5 \%$ in the variables online encyclopedias, blogs, scientific repositories and elearning platforms. The 2 nd year group presented the highest use frequency in all the cases. When comparing the use frequency of digital educational resources between the 2 nd and the 3rd year student groups, significant differences were identified in the 
variable social networks, in which the 2nd year student group presented the highest use frequency.

The classification of digital educational resources and of their use in the support to course units was carried out based on the students' opinions translated into adjectives. In order to treat the data, we defined as analysis unit each adjective stated in the answers and we defined the following categories: support to learning, resources specificities, resources potentialities, and others. As examples of the adjectives included in each category, we highlight: support to learning: support, help, essential, important, useful and crucial; resources specificities: appealing, flexible, enthralling, practical, quick and simple; resources potentialities: research, cooperation, exploration, communication and interaction. The categories found to be the most representative of the subjects' answers in the classification of digital educational resources were support to learning and resources specificities.

This study reveals that students recognize the great value of digital educational resources in the support to learning and that many of these are used many times or always by the majority of students. We also point out that in the classification of the resources, students give particular attention to general aspects of their use, to their specific characteristics and to their potentialities.

In the light of the results presented, and given the support, the characteristics and the potentialities that undergraduates value in digital educational resources, we think that these resources must continue to have an increasing importance within the context of higher education.

\section{References}

[1] Davidson, C. and Goldberg, D. (2009), The future of learning institutions in a digital age. Massachusetts: The MIT Press

[2] Ramos, J., Teodoro, V., Fernandes, J., Ferreira, F. and Chagas, I. (2010), Portal das Escolas - Recursos educativos digitais para Portugal: Estudo estratégico. Lisboa: Gabinete de Estatísticas e Planeamento da Educação (GEPE)

[3] Littlejohn, A., Falconer, I. and Mcgill, L. (2008), Characterising effective eLearning resources. Computers \& Education, $\mathrm{n}^{\circ}$ 50, pp. 757-771

[4] Cesteros, A. , Romero, E. and Ranero, I. (2012), Diez criterios para mejorar la calidad de los materiales didácticos digitales. In Actas de las VII Jornadas Campus Virtual UCM: valorar, validar y difundir Campus Virtual., pp. 25-34. Madrid: Universidad Complutense de Madrid, http://eprints.ucm.es/20241

[5] Dahlstrom, E., Walker, J. and Dziuban, C. (2013), with a foreword by G. Morgan. ECAR study of undergraduate students and information technology (research report). Louisville, CO: EDUCAUSE Center for Analysis and Research, disponível em http://www.educause.edu/ecar

[6] Ramos, J., Teodoro, V. and Ferreira, F. (2011), Recursos educativos digitais: reflexões sobre a prática. Cadernos
SACAUSEF VII, pp. 11-34. Lisboa: Ministério da Educação e Ciência, disponível em http://www.crie.minedu.pt/index.php?section $=402 \&$ module $=$ navigationmodule

[7] Connaway, S., Lanclos, D. and Hood, E. (2013), I always stick with the first thing that comes up on Google... Where People Go for Information, What They Use, and Why”. EDUCAUSE Review Online

[8] Wetzler, P., Bethard, S., Leary, H., Butcher, K., Danesh, S., Zhao, J., Martin, J. and Sumner, T. (2013), Characterizing and predicting the multifaceted nature of quality in educational web resources. ACM Transactions on Interactive Intelligent Systems, Vol. 3, No. 3, article 15

[9] Yang, L. (2014), Integration and utilization of digital learning resources in community education. In L. Shaozi, J. Qun, J. Xiaohong, J. Park (Eds) Frontier and Future Development of Information Technology in Medicine and Education, ITME 2013, pp. 2953-2959. Springer Science+Business Media Dordretch, http://dx.doi.org/10.1007/978-94-007-7618-0_375

[10] Carneiro, R., Rodrigues, A., Matos, J., Almeida, J. and Melo, R. (2010), Recursos educativos digitais: um serviço público. Lisboa: CEPCEP, Universidade Católica Portuguesa

[11] Fernández-Pampillón, A. (2013), A new AENOR project for measuring the quality of digital educational materials. TEEM'13 Proceedings of the First International Conference on Technological Ecosystem for Enhancing Multiculturality, pp. 133-139. Salamanca: Universidad de Salamanca

[12] Hylén, J. (2007), Digital Learning resources - possibilities and challenges for the school. Ed. Swedish Agency for School Improvement

[13] Pinto, M. (2007), Evaluación de la cálidade de recursos electrónicos educativos para el aprendizaje significativo. Cadernos SACAUSEF n ${ }^{\circ}$ 2, pp 25-42

[14] Wiley, D., (2000), Connecting learning object to instructionsl design theory: A definition, a metaphor, and a taxonomy, Utah State University Learning Environments Research Group, Logan

[15] Tarouco, L., Fabre, M., Tamusiunas, F., (2003), Reusabilidade de objetos educacionais, Disponível em: http://www.cinted.ufrgs.br/renote/fev2003

/artigos/marie_reusabilidade.pdf

[16] Moraes, R. (1999), Análise de conteúdo, Revista Educação, Porto Alegre, $\mathrm{n}^{\circ} 37$

[17] Bardin, L., (2013), Análise de conteúdo, Edições 70

[18] Creswell, J. (2014), Research design: Qualitative, quantitative, and mixed methods approaches (4th ed.). London: SAGE Publication Ltd

[19] Kumar, R. (2011), Research methodology: A step-by-step guide for beginners. London: SAGE Publication Ltd 